Vol. 9, $n^{\circ} 2 \mid 2005$

Varia

\title{
Mario Da Passano (1946-2005)
}

\section{Mario Sbriccoli}

\section{OpenEdition}

Journals

Édition électronique

URL : https://journals.openedition.org/chs/348

DOI : $10.4000 /$ chs.348

ISSN : 1663-4837

Éditeur

Librairie Droz

\section{Édition imprimée}

Date de publication : 1 décembre 2005

Pagination : 156-157

ISBN : 978-2-600-01054-2

ISSN : 1422-0857

Référence électronique

Mario Sbriccoli, « Mario Da Passano (1946-2005)», Crime, Histoire \& Sociétés / Crime, History \& Societies [En ligne], Vol. 9, n² | 2005, mis en ligne le 11 février 2009, consulté le 25 mars 2022. URL : http:// journals.openedition.org/chs/348; DOI : https://doi.org/10.4000/chs.348

Ce document a été généré automatiquement le 25 mars 2022

(C) Droz 


\title{
Mario Da Passano (1946-2005)
}

\author{
Mario Sbriccoli
}

1 Mario et moi étions de vrais amis. Pourtant, notre amitié avait un caractère bien particulier. Si nous nous connaissions depuis trente ans, ce n'est pourtant que depuis une dizaine d'années que nous avons pris l'habitude de nous rencontrer régulièrement. Une profonde affinité, affermie au fil du temps, et une sympathie réciproque nous unissaient en raison de nos expériences culturelles semblables, voire parallèles.

2 Nous partagions un champ d'étude privilégié : l'histoire du pénal, sur laquelle nous convergions intellectuellement, malgré une approche méthodologique fort différente. Mario a été le plus grand historien de la législation pénale que l'Italie ait connu. Ses études sur les codes d'avant le Risorgimento, sur la législation du royaume italien, sur le code de 1889 ou sur les juristes engagés dans ces productions législatives, se sont imposées par leur nombre et leur qualité. De plus, il a été le meilleur, en raison du projet général de son travail, ainsi que par les clefs interprétatives qu'il a forgées.

3 France, Italie révolutionnaire et impériale, Italie avant le Risorgimento, royaume d'Italie : reconstruire ainsi dans cette chronologie le processus de codification pénale a été un gigantesque travail d'archive, détaillé, constant, minutieux et appronfondi, avec des résultats scientifiques particulièrement substantiels, dont on mesure la portée dans la quantité de données accumulées. En résulte la mise en lumière d'un processus historique convaincant qui restera comme un des grands acquis de son travail. Ses recherches sur la législation en Toscane, entre la Leopoldina et la fin du Grand Duché, constituent un modèle historiographique in progress dont les résultats peuvent être considérés comme définitifs.

Mais Da Passano ne s'est pas limité à ces reconstructions soigneuses et documentées. Il leur a donné tout leur sens critique sur le plan de l'histoire législative, à travers deux exemples explicatifs particulièrement importants : la peine de mort et la prison. En outre, quelques figures de juristes - je pense notamment parmi d'autres à celle de Mancini - lui ont permis d'opérer un lien avec les expériences législatives, ce qui donne à ses reconstructions systématiques le sens quasi organique de la continuité épistémologique. 
Les travaux d'histoire pénale de Mariano Da Passano recèlent une autre caractéristique qui singularise sa sensibilité d'historien. Il s'agit de son attention vigilante aux liens serrés entre le pénal et le «monde des subalternes»-premiers destinataires historiques de la répression. Ce souci social et méthodologique ressort tout particulièrement de son dernier travail encore inédit: "Delitto di Regina Coeli», richement documenté et traversé par une tension politique forte et passionnée. Mario dépassait largement l'évidence documentaire. Sa démarche historique donnait sens aux événements qu'il replaçait dans un vaste contexte culturel, comme il l'avait fait avec les raisonnements sur les méthodes, la fonction de la répression de l'État libéral du XIX ${ }^{\mathrm{e}}$ siècle, les considérations politiques sur l'usage des forces policières agissant en de larges espaces arbitraires, sur les contradictions de l'État dit de droit. De tels événements qui semblent (ou semblaient) extraordinaires au point de se situer à la limite d'événements considérés comme de simples faits divers, acquièrent chez $\mathrm{Da}$ Passano un sens tout autre, car il les analyse de manière plus générale pour en démontrer la banale historicité et la probabilité politique.

Finalement, je terminerai ce bref hommage mémoriel en rappelant une autre qualité du travail historique de Mario Da Passano. Je veux parler de l'ironie qui nourrit maints passages de son œuvre. Ironie qui fonctionne de manière sérieuse et fonctionnelle dans le développement de son écriture. Je crois que Mario mettait en effet de la passion et de la foi dans son travail. Il n'était pas un «historien académique ", ni, comme on le dit parfois, un «historien professionnel». Il était encore moins un historien routinier. Il n'appartenait pas aux rangs de ceux qui pensent que les historiens doivent être objectifs, avant d'échanger leur «objectivité » avec la plus stérile froideur. Tout au contraire, Mario Da Passano était un historien passionné qui, dans ses écrits, mettait en exergue les vers des poètes et des musiciens qu'il aimait.

\section{AUTEUR}

\section{MARIO SBRICCOLI}

(Università di Macerata) 